\title{
TEXTBOOK ANALYSIS ON COLLEGE ACADEMIC WRITING
}

\author{
Handoyo Puji Widodo \\ Politeknik Negeri Jember, Jember
}

\begin{abstract}
When no specific materials are available particularly on EFL writing courses, the selection and use of a textbook are of great priority. For this reason, this article analyzes a textbook on college academic writing in an EFL contextIndonesia. In this analysis, I employed the in-depth method using the three phases of the textbook analysis, concerning the three main features of the textbook: (1) goal and organization, (2) contents-inputs, models, and exercises, and (3) the suitability of the textbook viewed from aims, beliefs about writing, the roles of the teacher, the role of the students, and the roles of the textbook as a whole. The extent to which the selected textbook reflected the recent views of the teaching and learning of writing skill was also investigated. The results show that the author echoed his clear goal and organization. The contents of the textbook regarding the inputs, models, exercises, and writing assignments reflected the features of academic writing required for college students.
\end{abstract}

Key words: academic writing, process writing, text functions

The status of writing in language teaching has accelerated tremendously since 30 years ago. In the teaching of writing, the sequence of activities typically involves: (1) familiarization: learners study grammar and vocabulary, usually through a text; (2) controlled writing: learners imitate given patterns, often from substitution tables; (3) guided writing: learners manipulate model texts; and (4) free writing: learners employ the patterns they have developed to write a letter, a paragraph, an essay, and the like (Richards, 2002). Writing in a second or foreign language is regarded as one of the most difficult skills for a learner to master, particularly in free academic writing. The difficulty is due to the need to generate and organize ideas using an appropriate choice of vocabulary, sentence, and paragraph organization and to turn such ideas into a readable text (Richards and Renandya, 2002). 
For this reason, there should be appropriate materials, which cater for the students' needs. Teaching materials are regarded as a key factor in most language programs (Richards, 2001). For teachers, textbooks or course books either required or supplementary provide content and teaching-learning activities, which shape much of what happens in the classroom (Celce-Murcia, 2001). Furthermore, Wright (cited in Lee, 2003: 165) says that teaching materials (e.g. textbooks) assist to define the goals of the syllabus and the roles of teachers and learners within the instructional process.

In EFL writing courses where no specific teaching materials for academic writing exist, the selection and use of a textbook or course book are crucial issues. Teachers, in this respect, are required to be able to make informed judgments about the textbooks and other related teaching materials (Richards, 2001; Lee, 2003). In other words, the selection and use of the textbook both required and supplementary is based on its analysis or evaluation.Language materials design and development take into account such factors as: teachers, learners, language use and function, tasks, designs, content, and adoption so that the teaching-learning activities are successfully conducted. In this line, this paper attempts to analyze a textbook on college academic writing in the context of EFL in Indonesia.

\section{METHODS FOR ANALYZING OR EVALUATING TEXTBOOKS}

In general, textbook analysis or evaluation could be carried out through three main methods: impressionistic, checklist, or in-depth methods (McGrath, 2002). First, the impressionistic method refers to achieving a general impression of the materials in the textbook. This analysis, as Stervick (cited in McGrath, 2002: 2526) suggests, includes: 1) three qualities: strengths - pay off for the learners, lightness-learnability, and transparency - clarity of organization and presentation; 2) three dimensions: linguistic, social, and topical; and 3) four essential components of lessons: opportunities for language use, sample of language, exploration of vocabulary, and exploration of phonological, orthographic or grammatical form. Second, the checklist method comprises three items, i.e. comparison, identification, or verification. This method is easy to do since teachers only check the list of the items while analyzing or evaluating a certain textbook. Last, the in-depth method encompasses such items as the aims and content of the materials, learners' needs, teachers' needs, and material functions as a classroom resource. In other words, this analysis deals with learner needs and interest, learner approaches to language learning, and the teaching-learning approach in the teacher's own classroom. 
Of the three methods listed above, I focus on analyzing or evaluating a textbook on academic essay writing, through the three-phase, in-depth method (Lee, 2003). In the first phase, the analysis includes the goal and organization of the textbook. In the second phase, the analysis focuses on contents (e.g. inputs, models, and exercises) of the textbook. In the last phase, the analysis deals with the suitability of the textbook with the aims, beliefs about writing, the roles of the teacher, the role of students, and the roles of the textbook as a whole in an EFL context, Indonesia. The textbook analysis is presented in Figure 1 below.

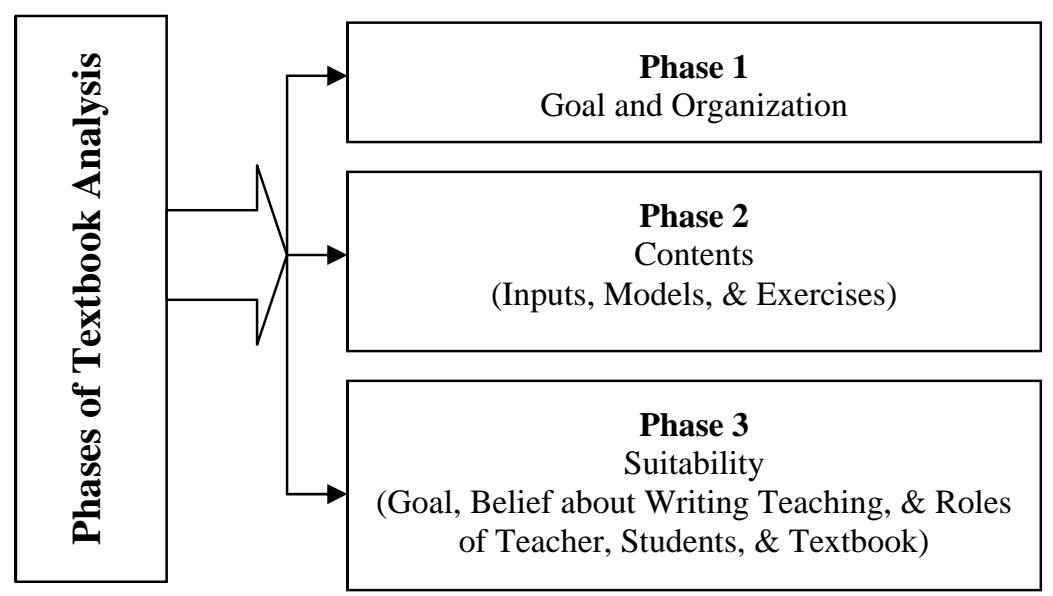

Figure 1: Phases of Textbook Analysis

In the following section, the extent to which the selected textbook reflects the recent views of the teaching and learning of writing skill is discussed in detail.

The textbook chosen is College Writing Skills written by John Langan. This textbook was published by The McGraw-Hill Companies, Inc in 1996 with the ISBN of 0-07-036442-7. This textbook has been chosen on the basis of my teaching experience in teaching writing as well as materials design and development for writing courses at college and university levels. 


\section{FINDINGS}

The Extent to which the Selected Textbook Reflects Recent Views of the Teaching and Learning of Writing Skill

The selected textbook on College Writing Skills reflects a process-based writing approach which focuses on how learners experience a series of activities or steps in writing. This approach is reflected in Chapter 1 of the textbook and the author's statement in the introduction. The author of the textbook treats writing as a process comprising four main stages: planning (pre writing), drafting (writing), and revising and editing. This is related to the process-based approach suggested by Seow (2002). The four stages of the writing process is presented in Figure 2.

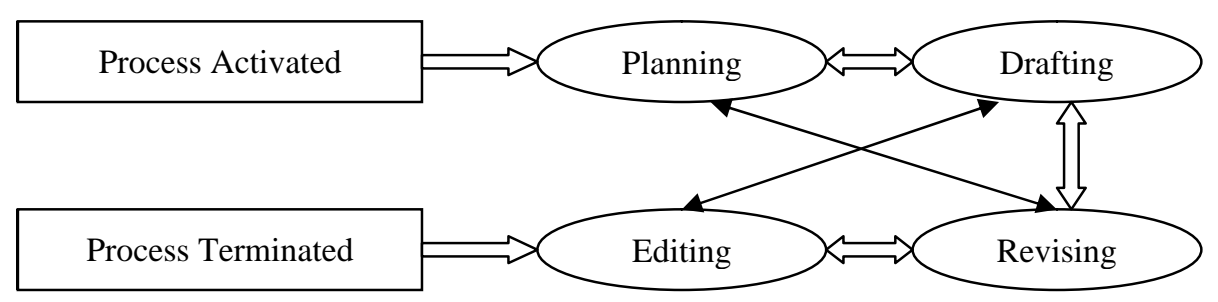

Figure 2. The Writing Process (Seow, 2002: 315)

Some authors (e.g. Dirby, Kirby, and Liner, 2004; Seow, 2002; and Terrible, 1996) also emphasize that process oriented writing, when implemented in the classroom, also should incorporate three other stages externally imposed on students by the teacher, i.e. responding, evaluating, and post writing (e.g. reading aloud, displaying, or publishing). Related to the three additional stages, the author of the textbook incorporates two activities, i.e. responding and evaluating essays through peer review. Such activities are the key aspects of the process-based approach, and they have a central role in the successful implementation of process writing, since they provide, students with an opportunity to improve their composition and to write better. More importantly, the students are trained to think critically. Is presented in Figure 3. 


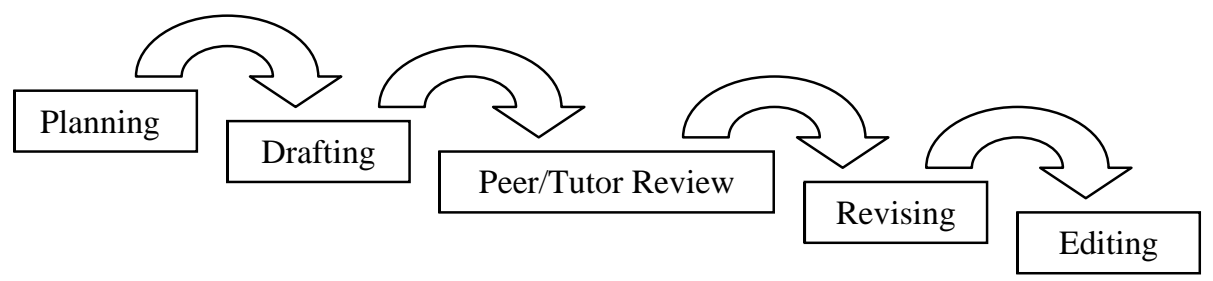

Figure 3: Cycle of Process Writing

Unfortunately, the author of the textbook does not recommend post writing activities, such as reading aloud, sharing, or publishing, as suggested by Dirby, Kirby, and Liner (2004); Hyland (2003); Seow (2002); and Terrible (1996).

Hyland (2003) concludes that the process approach to teaching writing emphasizes learners as the independent writers of texts so that a teacher allows her/his students' to develop their abilities to plan, define a rhetorical problem, and propose and evaluate solutions. Response is crucial in assisting learners to move through the stages of the writing process; therefore, various means of providing feedback are used, including teacher-student conferences, peer response, audio taped feedback, and reformulation.

In addition to incorporating the process-based approach, the author sees writing as a functions or the means for achieving the ends (purposes) of writing as Hyland (2003) points out. In this respect, the author introduces different patterns of essays, in Chapter 2: Types of Essay Development. In this chapter, the author describes such functional patterns of essays as: description, narration, examples, process, cause and effect, comparison and contrast, definition, division and classification, and argumentation. The author believes that such patterns are fundamental to academic writing for college students. They should enable student to develop effective essays through the creation of introductory, body, and concluding paragraphs as well as transitions and develop different types of essays. To sum up, texts could then be seen as composed of structural entities such as Introduction-BodyConclusion, and particular organizational patterns such as narration, description, and argumentation are discussed and practiced.

In conclusion, the author views writing as a process since the students need to go though some activities, and as text functions in developing different types of essays. In short, the author views writing not only as a process, but also as an en- 
deavor to communicate in social context in which he tries to encourage learners to use language patterns to achieve coherent, purposeful composition.

\section{The Appropriateness of Goals, Organization, and Contents of The Selected Textbook}

The first phase analysis focuses upon the appropriateness of the goal and organization of the textbook, and the second phase analysis concentrates on the appropriateness of the contents of the textbook.

\section{Goal}

Regarding the goal, the author states that "College Writing Skills will help students master the traditional five-paragraph essay. It is a very practical book with a number of special features to aid instructors and students (p. xi)." One of the features indicating that the textbook is process-based is that the author mentions "Writing is treated as a process. The second chapter, "Important Factors in Writing," discusses prewriting, rewriting, and editing. In addition, many writing assignments are accompanied by "Suggestions on How to Proceed" that give stepby-step directions in the process of writing an essay." In addition, from the phrase "the traditional five-paragraph essay," we could conclude that the students need to know three general surface structures of an essay, that is, one introductory paragraph, two body paragraphs, and one concluding paragraph. In this respect, the author also emphasizes that the students should come up with such a format through a series of activities or a process. Another feature that the author incorporates a text function-based approach is found in the second chapter of the textbook (pp. 121122 and 124) which discusses the paragraph-pattern essays. To sum up, the goal of the textbook is clearly stated along with the essential features of the textbook.

\section{Organization}

In terms of the organization, the textbook was published in 1996 to aid in the teaching and learning of academic writing particularly for college students in an international context. The textbook, as the core material, as accompanied by three supplementary materials, i.e. Instructor's Edition - made up of the student text, Instructor's Guide featuring hints to the instructor, a model syllabus, and answers for all the activities and tests in the text and Instructor's Manual and Test Bank- 
including material in the Instructor's Guide along with thirty supplementary activities and tests in which such activities and tests offer practice in a wide range of skills covered in the textbook, from generating and narrowing a thesis to outlining essays to editing papers for common mistakes in grammar. The textbook offers color printing only on the headline of each point. The textbook is structured into four chapters. The first chapter-Basic Principles of Essay Writing comprises: (1) Introduction to the Essay Form, (2) Important Factors in Writing, (3) The First and Second Steps in Essay Writing, (3) The Third and Fourth Steps in Essay Writing, and (4) Four Bases for Evaluating Essays; each sub-chapter is consistently accompanied with some arguments and clear instructions. The second chapterTypes of Essay Development discusses nine main patterns of essay development (description, narration, examples, process, cause and effect, comparison and contrast, definition, division and classification, and argumentation) in which each pattern of essay development succinctly comprises: a short input (explanation), a model essay, classroom activities, and writing assignments. The third chapterSpecial Skills provides explanations about taking essay exams, writing a summary, writing a report, writing a resume and job application letter, using the library, and writing a research paper. With such skills, I think that the author is committed to developing students' writing skills by providing additional writing skills, which could support the students' learning needs (i.e. taking essay exams and writing a report) and their future career (e.g. writing a resume and job application letter). Each description of the skills is consistently accompanied with models and activities. The fourth chapter-Handbook of Sentence Skills offers explanations about grammar, mechanics, punctuation, and word use (vocabulary); each of which is accompanied with activities and review tests. Additionally, this chapter treats practice, which focuses on editing tests for sentence-skills mistakes consisting of 12 editing tests with clear directions.

In conclusion, the textbook is clearly and consistently organized along with its activities. The organization of the textbook reflects its goal and requirements of academic writing for college students.

\section{Contents}

In the second phase, I now continue my analysis procedure by carrying out an in-depth analysis in order to investigate the explicit nature (i.e. contents) of the chapters in the selected textbook. As previously mentioned, the textbook is divided into 4 chapters: (1) Basic Principles of Essay Writing, (2) Types of Essay Devel- 
opment, (3) Special Skills, and (4) Handbook of Sentence Skills in which such chapters provide sufficient classroom activities and writing assignments. Nevertheless, in this sense, only two chapters (Basic Principles of Essay Writing and Types of Essay Development) are thoroughly analyzed. This analysis meets McDonough and Shaw's suggestion (cited in Lee, 2003: 174) that:

In order to perform an effective internal inspection of materials, we are required to examine at least two units of a piece or set of materials. This also enables us to find out any characteristic relationship between chapters or units in the textbook.

Chapter 1 and Chapter 2 have been chosen since the two are fundamental aspects for writing academic essays, particularly for college students of intermediate level. Chapter III Special Skills could be treated to equip students with further writing skills, and Chapter IV could be treated as part of references for sentence problems, which exist in students' essays.

Arriving at a closer inspection of the sequence of activities included in Chapters 1 and 2, each chapter starts with points which will be discussed. In detail, Chapter 1 is divided into five sub-chapters, including (1) Introduction to the Essay Form - explaining the importance of supporting a point in writing, the difference between a paragraph and an essay, and the general structure of an essay; (2) Important Factors in Writing - discussing the importance of your attitude about writing, developing a subject, keeping a journal, prewriting, outlining, revising, editing, and proofreading; (3) The First and Second Steps in Essay Writing - showing how to start an essay with a thesis and support the thesis with specific evidence/details; (4) The Third and Fourth Steps in Essay Writing - providing explanations about organizing and connecting specific details in the body paragraph(s) of an essay, starting and ending an essay with effective introductory and concluding paragraphs, and writing clear, error free sentences; and (5) Four Bases for Evaluating Essaysexplaining how to evaluate an essay for unity, support/details, coherence, and sentence skills. I think that the sequence of the sub-chapters in Chapter 1 gives basic understanding to students how to write an essay consisting three levels: introductory, body, and concluding paragraphs; this is consistent with the author's goal that "...help students master the traditional five-paragraph essay (p. xi)." It is also worth noting that the author provides pre writing techniques, such as brainstorming, free writing, diagramming, making a list, preparing a scratch outline, and outlining. Such techniques will enable students to have opportunities for methods of generating ideas, as Raimes (2002) suggests. Furthermore, the author's explana- 
tions about the introductory paragraph — consisting of a general statement and thesis; the body paragraphs - developing the thesis stated in the introductory paragraph along with the relevant details; and the concluding paragraph are well introduced. Such concepts along with the exercises will assist the students to comprehend and write an essay easily. Interestingly, in sub-chapter 4-Four Bases for Evaluating an Essay, the author reminds students/learners of other essential aspects of writing an essay; four of which are unity, coherence, details, and grammar by supplying the evaluation checklists for an essay. According to Raimes (2002), this will encourage the students to be involved in editing and proofreading activities. Of the five sub-chapters, the author provides succinct explanation or input session, model or example of the input, and exercises. The four forms of activities allow the students to have input and practice so that they are well prepared for the next chapter, that is, Types of Essay Development, for example. Unfortunately, the author does not provide assignments for students to reinforce the materials in each subchapter so that they could do some exercises outside the classroom. Regardless of this shortcoming, in Chapter 1, the author assigns the students to write an essay that include ... required points.

Chapter 2 is divided into 10 sub-chapters, including (1) Introduction to Essay Development-discussing definitions of the patterns of essays explained later on, point of view in writing, writing for specific purpose and audience, peer review, and essay checklists; (2) Description, (3) Narration, (4) Examples, (5) Process, (6) Cause and Effect, (7) Comparison and Contrast, (8) Definitions, (9) Division and Classification, and (10) Argumentation. In terms of point of view in writing, the author mentions three approaches or points of view; three of which are first person (e.g. I, me, mine, we, our, and $u s$ ), commonly used in narrative essays based upon personal experience; second person (i.e. you), generally found in a process or procedure essay; and third person (e.g. she, he, her, him, they, their, and them), commonly found in most of the academic essays. In this sense, the author tries to remind students of appropriate use of pronouns in writing an academic composition.

It could be concluded therefore, that the author applies the text function-based approach to selecting the types of essays, which are assigned to students or on which the students work. It is quite interesting to observe that the author instructs the students to outline their draft before they develop an essay and use peer review before their assignments are submitted. The us of peer review, indicates that the author considers writing as a process, which requires prewriting and feedback from others as important elements in writing a better essay. Furthermore, the author believes that peer review offers some benefits. This idea is compatible with Hyland's 
(2003: 199) statement that such an activity will encourage students to participate actively, get involved in authentic communicative context, and develop critical reading skills. To facilitate peer review, the author provides checklists for essay feedback for the teacher and the learners and essay evaluation for the teacher.

The core materials of the second chapter are the types of essay development. In this respect, the author provides the input, models, exercises, and writing assignments. In the input, the author provides a short introduction to types of essay by giving models. Some topics (i.e. basement or garage, exam room, shyness, love, how to gain or lose weight, how to relax, punishment for certain crimes, two teachers, two games, team player, optimist, clothing, school subjects, lower attendance, and missing school to go to work) are familiar with the students, so they could easily draft or develop an essay. To know whether the students understand the concept, the author provides exercises in terms of essay structures explained in Chapter 1. Besides, the writing assignments are provided for writing independently on the basis of one of the topics given. The focus is on having the students develop a type of essay assigned for outside-classroom activities.

To sump, in Chapters 1 and 2, the author divides the chapters into subchapters in which each sub-chapter consistently comprises: inputs, models, exercises, and writing assignments. The inputs and models are clearly explained along with some problems. The author emphasizes sequential steps for developing patterns of essays on the basis of the writer's purposes. I think that the author provides essay topics that are quite familiar with EFL college students particularly in Indonesia.

\section{DISCUSSION OF THE FINDINGS}

\section{The Suitability of The Selected Textbook with The EFL College Students in Indonesia}

In this last phase, I would like to make an attempt of drawing together the various aspects of the textbook as previously noted at Phases 1 and 2, and I would suggest the underlying goal, beliefs about writing, the roles of the teacher, the role of students, and the roles of the textbook as a whole, as Richards (2001) emphasizes. 


\section{Goal}

Drawing from the analyses in the phases 1 and 2, it is obvious that the core goal of the textbook is the development of the college students' essays in English, concentrating on writing good essays of different types through the integrated approach: process and text function based writing. The exercises included in the textbook are intense. For instance, in Chapter 1, the author consistently provides some exercises after the input and its model are given, and in Chapter 2, he provides not only classroom exercises, but writing assignments as well in which some activities include peer review. In this sense, it could be viewed that the author tries to encourage students to think critically and to work independently without relying too much on the teacher, and the author believes that writing should be considered as a process as mentioned in the key features of the textbook, and he assures that student writers' ideas could be written on the basis of certain purpose and audience. From the two chapters, it is apparent that the author is highly committed to the goal prescribed in the introduction of the textbook. I think the textbook meets the needs of college students who would like to write an essay at either an intermediate or post-intermediate level.

\section{Belief about Writing}

The author's belief about writing could be presented in the content of the textbook and may influence the methodology. As previously described in Phases 1 and 2, the methodology is characterized by a basic standardized pattern in which each concept starts with inputs, models, and exercises. The essay writing element also shows an underlying belief about rhetorical writing regarding general structure of a composition (an essay), idea organization, and syntactic patterns. The patterns of the essays indicate types of essays (e.g. description and argumentation), which determine the writer's purposes mostly found in academic settings. In other words, the author clearly sees writing as a medium of communication in different purposes to render a purposeful, communicative composition. He also views writing as a process through the creation of seven important elements in the essay, such as surface structure of essays (i.e. introductory, body, and concluding paragraphs) and idea organization (e.g. unity, coherence, detail, and grammar) in which the students have to develop a set of strategies for planning, drafting, revising, and editing. The process approach is used to furnish useful support for the students in achieving greater control over the cognitive strategies employed in writing. On the other hand, in Chapter 2 the author provides many writing assignments for developing 
patterns of essays assigned without considering or suggesting time allocation and opportunity for students to have thorough feedback. Aside from such a drawback, the exercises designed by the author reflect a process in which the students are required to go through intensive writing work. The author's belief about writing is compatible with the context of EFL college students in which the process is of great priority supported with the clarity of goals of writing a certain composition (e.g. an essay) on the basis of purpose and audience.

\section{The Roles of the Teacher}

Since the textbook is accompanied with the three supplementary textbooks, namely, Instructor's Edition, Instructor's Manual, and Test Bank as previously mentioned in Phase 1, this indicates that a teacher serves as a facilitator or resource, monitor, motivator, feedback provider, and evaluator. As a facilitator or resource, the teacher provides some inputs that are learnable or comprehensible for the students; s/he is required to select useful exercises or activities for the students. As a monitor, the teacher is required to monitor students' activities because there are numerous activities to be done by the students. As a motivator, since the students go through intense activities, the teacher needs to motivate the students to write better and cooperate with one another and with the teacher. As feedback provider and evaluator, the teacher should provide some comments or suggestions on the students' work, and then he could evaluate the students' essays as a result of the feedback given.

Since the inputs and input models are given prior to the exercises or assignments, the teacher is required to help the students to comprehend the inputs and the model/examples provided. With the supplementary textbooks given, the teacher feels more confident in solving some problems in the exercises. In spite of this, s/he has to be able to wisely and thoroughly arrange the time in the classroom and evaluation for the students. It seems to me that, for an EFL teacher, this textbook provides clear models and standard answers, which are internationally standardized, and could motivate the teachers to design and develop writing materials. In this case, the teacher could further serve as materials designer, developer, or evaluator. 


\section{The Roles of Students}

From the organization and content of the textbook particularly in Chapters 1 and 2, focusing on essays, it is suggested that the students begin writing an essay with a clearly stated thesis; provide logical, detailed support for their thesis; organize the supporting materials effectively; and revise and edit carefully so that the essay is presented in clear, error free sentences. In this sense, it could be obviously seen that the students serve as competent planners, writers, and feedback providers of their essays and others' essay in a peer review activity. In other words, the author believes that the students could serve not only as planners and writers but also feedback providers. I think involving students as feedback providers means empowering them in thinking critically. In other words, the author of the textbook tries to inspire the students to get started writing better.

\section{The Roles of the Textbook}

Since all of the concepts, models, and exercises along with the Instructor's Edition are provided, the textbook serves not only as an informant but also as a useful guide or reference to facilitate teaching-learning process both in the classroom and outside the classroom. In short, the principal role of the textbook as a whole is to organize the teaching and learning of English essays for college students. The textbook could serve as a source of learning for students particularly in an EFL context.

\section{CONCLUSION AND SUGGESTIONS}

In conclusion, the analysis in Phase 1 indicates that the author has echoed his clear goal and organization. The analysis in Phase 2 shows the contents of the textbook in terms of the inputs, models, exercises, and writing assignments. Last, the analysis in Phase 3 enables proves that the textbook is suitable regarding such issues as: goal, belief about writing, the roles of the teacher, the roles of the students, and the roles of the textbook as a whole, as Richards (2001) and Raimes (2002) point out. On the basis of the analyzes above, I recommend that the textbook be used as one of the learning sources especially in college essay writing courses either core or supplementary in the context of EFL. 


\section{REFERENCES}

Celce-Murcia, M. 2001. Teaching English as Second or Foreign Language ( $3^{\text {rd }}$ edition). Boston: Heinle \& Heinle.

Coffin, C., M.J. Curry, S. Goodman, A. Hewings, T. Lillis, and J. Swann. 2002. Teaching Academic Writing: A Toolkit for Higher Education. London: Routledge.

Hyland, K. 2003. Second Language Writing. New York: Cambridge University Press.

Kirby, D., D.L. Kirby, and T. Liner. 2004. Inside Out: Strategies for Teaching Writing $\left(3^{\text {rd }}\right.$ edition). Portsmouth: Heinemann.

Lee, Y. 2003. A package for an English paragraph: An evaluation of the coursebook used in two EFL writing courses. English Teaching 58/3: 165 - 188.

McDonough, J. and C. Shaw. 2000. Materials and Methods in ELT: A Teacher's Guide. Oxford: Oxford University Press.

McGrath, I. 2002. Materials Evaluation and Design for Language Teaching. Edinburgh: Edinburgh University Press Ltd.

Raimes, A. 2002. Ten steps in planning a writing course and training teachers of writing. In J. C. Richards and W. A. Renandya (eds.), Methodology in Language Teaching: An Anthology of Current Practice (pp. 306-314). Cambridge: Cambridge University Press.

Richards, J.C. 2001. Curriculum Development in Language Teaching. Cambridge: Cambridge University Press.

Richards, J. C. 2002. 30 years of TEFL/TESL: A Personal Reflection. RELC Journal 33/2: $1-33$.

Richards, J.C. and T. Rodgers. 2001. Approaches and Methods in Language Learning ( $2^{\text {nd }}$ edition). New York: Cambridge University Press.

Richards, J.C. and W. A. Renandya. 2002. Methodology in Language Teaching: An Anthology of Current Practice. Cambridge: Cambridge University Press.

Seow, A. 2002. The writing process and process writing. In J. C. Richards and W.

A. Renandya (eds.), Methodology in Language Teaching: An Anthology of Current Practice (pp. 315-320). Cambridge: Cambridge University Press.

Terrible, C. 1996. Writing. Oxford: Oxford University Press. 